\title{
Analysis of bending strength of porous titanium processed by space holder method
}

\author{
V. Amigó ${ }^{1}$, L. Reig ${ }^{2}$, D. J. Busquets*1, J. L. Ortiz ${ }^{3}$ and J. A. Calero ${ }^{4}$
}

\begin{abstract}
Porous titanium specimens have been produced by means of the space holder method. Titanium grade 3 (TiCP3) has been used as material and ammonium bicarbonate as spacer. Process parameters (compaction pressure, metal grain size range and spacer volume) influence on porosity morphology and distribution and bending strength has been analysed. The results denote an important loss of strength when comparing samples sintered without and with spacer. On the other hand, a higher bending strength was observed in the porous samples with a smaller size of ammonium bicarbonate particles. Finally, the evolution of bending strength with the compaction pressure depends on the spacer volume, having a direct dependency for reduced amounts and inverse for higher contents.
\end{abstract}

Keywords: Porous titanium, Space holder, Metallic implants, Stiffness, Bending strength

\section{Introduction}

The excellent biocompatibility and mechanical properties of titanium and titanium alloys have promoted many applications in the field of biomedicine. Among others, it is nowadays being used in the manufacture of fixation systems for bone regeneration and replacement devices, like orthopedic prosthesis, dental implants and other devices as pacemaker housings. ${ }^{1,2}$

While metallic implants are in contact with bone, this is reconstructed by both the replacement of old bone in damaged areas and the growth of new osseous tissue. However, for this regeneration to take place in a healthy manner and therefore imparting enough strength to the joint, it is necessary to stimulate osteoblasts (i.e. those cells that regenerate bone) by application of some degree of stress. ${ }^{3,4}$ In fact, bone is a living tissue that reacts against external forces by strengthening. On the other hand, when either because of the implant design or the inherent properties of the biomaterial the implant is too stiff, bone does not regenerate itself in a suitable form, leading to its weakening and relaxation. ${ }^{3-5}$

Despite the fact that titanium and its alloys show the best combinations of strength, ductility, elastic module and corrosion resistance of the metallic materials used as implants, ${ }^{5}$ their Young's modulus $(100-110 \mathrm{GPa})^{6}$ is still very high in comparison to that of human bone (10$30 \mathrm{GPa}){ }^{6,7}$ For this reason, the research trends in the

${ }^{1}$ Departamento de Ingeniería Mecánica y de Materiales, Universidad Politécnica de Valencia, Camino de Vera s/n, 46022 Valencia, Spain ${ }^{2}$ Departamento de Ingeniería Mecánica y Construcción, Universidad Jaime I de Castellón. Av. de Vicent Sos Baynat, s/n, 12071 Castelló de la Plana, Spain

${ }^{3}$ Departamento de Mecatrónica, Instituto Tecnológico y de Estudios Superiores de Monterrey, Campus Querétaro, Epigmenio González 500, 76130 Santiago de Querétaro, Mexico

${ }^{4}$ Aleaciones de Metales Sinterizados SA (AMES), San Vicenç dels Horts, Barcelona, Spain

*Corresponding author, email dbusquets@mcm.upv.es last years have been to develop titanium porous components with the purpose of reducing stiffness as well as stimulate osseointegration. These new developments result in an improvement in the behaviour at the bone/metal interface. ${ }^{4,6}$

There are numerous manufacturing processes for producing porous titanium components. ${ }^{6,8-12}$ Among them, the space holder method is able to produce components with a high level of porosity $(35-80 \%)$ distributed homogeneously throughout the volume. ${ }^{12}$ Although there the porosity is reduced on the surface, the inner porosity allows a significant stiffness reduction. ${ }^{6,10}$

In this work, porous titanium grade 3 samples were produced by the space holder method. The effects of main process variables (compaction pressure, volume and spacer particle size) on bending strength and stiffness were investigated.

\section{Experimental}

\section{Sample preparation}

Titanium powder produced by the hydride-dehydride process, with a particle size smaller than $45 \mu \mathrm{m}$ ( -325 mesh) was used. The reported chemistry of the alloy was $\mathrm{Ti}-0.04 \mathrm{Fe}-0.003 \mathrm{Mn}-0.02 \mathrm{Mg}-0.04 \mathrm{Si}-0.04 /$ $0 \cdot 08 \mathrm{~N}-0 \cdot 3 \mathrm{O}-0 \cdot 4 / 0 \cdot 5 \mathrm{H}-0 \cdot 017 \mathrm{C}$. The pore former additive was ammonium bicarbonate, $\mathrm{NH}_{4} \mathrm{HCO}_{3}$, which decomposes in air at temperatures above $60^{\circ} \mathrm{C}$ by reaction $(1)^{11}$

$$
\mathrm{NH}_{4} \mathrm{HCO}_{3} \rightarrow \mathrm{NH}_{3}+\mathrm{CO}_{2}+\mathrm{H}_{2} \mathrm{O}
$$

$\mathrm{NH}_{4} \mathrm{HCO}_{3}$ powder was milled in an agata mortar and sieved to separate two different particle size fractions of $250-500 \mu \mathrm{m}$ and $500-1000 \mu \mathrm{m}$. Mixtures of TiCP3 with both ranges of spacer were obtained by using a ' $\mathrm{V}$ ' mixer during $1200 \mathrm{~s}$ at $3.98 \mathrm{rad} \mathrm{s}^{-1}\left(38 \mathrm{rev} \mathrm{min}{ }^{-1}\right)$. The $\mathrm{NH}_{4} \mathrm{HCO}_{3} / \mathrm{TiCP} 3$ ratios utilised were the following (in vol.- $\%$ ): $0: 100,30: 70,40: 60,50: 50,60: 40$ and $70: 30$.

(C) 2009 Institute of Materials, Minerals and Mining 


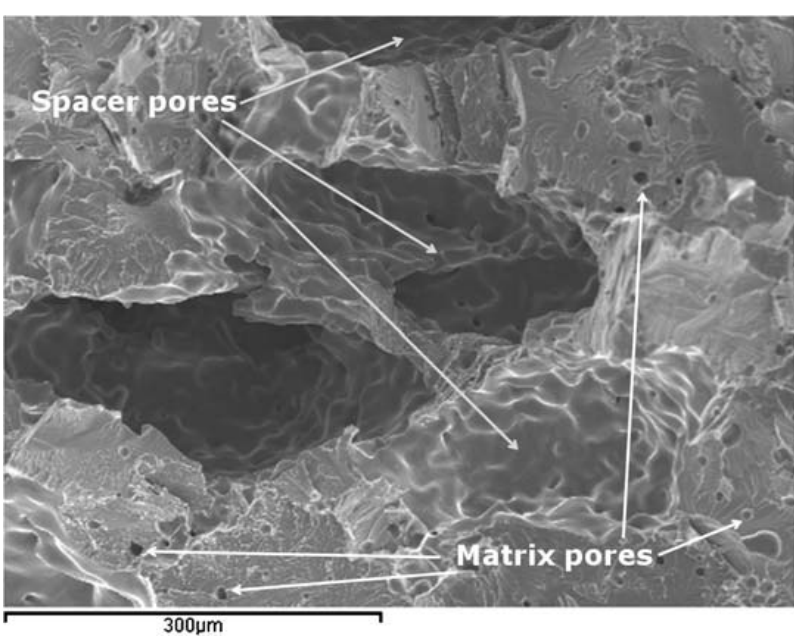

1 Matrix and spacer pores of TiCP3 with 30 vol.-\% space holder, obtained with compaction pressure of $300 \mathrm{MPa}$ and sintered

Then, the different mixtures were uniaxially compacted at pressures of 100 and $200 \mathrm{MPa}$ in a cylindrical die with an internal diameter of $25 \mathrm{~mm}$. To eliminate the space holders and previous to the sintering cycle, the green bodies were heated in air at a temperature of $80^{\circ} \mathrm{C}$ during $21 \mathrm{~h}$. Finally, all the samples were sintered at $1300^{\circ} \mathrm{C}$ for $2 \mathrm{~h}$, in a vacuum furnace $\left(10^{-2}-10^{-3} \mathrm{~Pa}\right)$.

After sintering, the cylinders were cut in a precision cutting machine to extract bending specimens (longitudinal direction) and disc samples (transversal direction) for microstructural observation and determination of porosity.

\section{Microstructure and porosity}

After metallographic preparation, samples were observed with a stereoscopy, a metallographic microscope and a scanning electron microscope (JEOL JSM6300 with an INCA EDX detector, by Oxford Instruments Ltd). The interconnected porosity was determined by the Archimedes method, according to ASTM B328-96 (2003).

\section{Three point bending test}

Bending tests were performed according to ISO 3325:2000 (ASTM E290-97a) standard using the three point method. Rectangular shaped samples of an average size of $21 \times 10 \times 5 \mathrm{~mm}$ were tested at room temperature, at a deformation rate of $0.5 \mathrm{~mm} \mathrm{~s}^{-1}$ using a distance between supports of $16 \mathrm{~mm}$.

The maximum bending strength (flexural strength), was calculated by using equation (2)

$$
\sigma_{\max }=\frac{3 P L}{2 b h^{2}}
$$

where $P$ is load in N, $L$ is distance between supports

Table 1 Summary of experimental conditions and sample codification

\begin{tabular}{llr}
\hline $\begin{array}{l}\text { Spacer size } \\
\text { range, } \mu \mathrm{m}\end{array}$ & $\begin{array}{l}\text { Compacting } \\
\text { pressure, MPa }\end{array}$ & Sample code \\
\hline $250-500$ & 100 & $250-500,100$ \\
$250-500$ & 200 & $250-500,200$ \\
$500-1000$ & 100 & $500-1000,100$ \\
$500-1000$ & 200 & $500-1000,200$ \\
\hline
\end{tabular}

(16 mm), $b$ is width $(9 \cdot 8 \pm 4 \mathrm{~mm})$ and $h$ is thickness $(5 \cdot 23 \pm 0 \cdot 58 \mathrm{~mm})$.

Stiffness was evaluated measuring the slope of the stress-strain curve.

\section{Results and discussion}

\section{Microstructure and morphology of pores}

Figure 1 shows a general appearance of the pore morphology of the samples. Two kinds of pores can be identified: spacer and matrix pores. Whereas the former are clearly produced by the decomposition of the space holder, the latter are formed because of the use of small compaction pressures.

As shown in Fig. 2, some samples presented a homogeneous distribution of macropores (Fig. 2a), while others showed an important pore coalescence and segregation (Fig. 2b), as clusters of space holder pores appeared in specific regions. This effect can be attributed to significant density differences between the bicarbonate $\left(1 \cdot 5 \mathrm{~g} \mathrm{~cm}^{-3}\right)$ and the TiCP3 powder $\left(4 \cdot 5 \mathrm{~g} \mathrm{~cm}^{-3}\right)$, and different particle size $($ TiCP3 $<45 \mu \mathrm{m}$; space holder powder $>250 \mu \mathrm{m})$. Furthermore, microscopic examinations show the irregular geometry and surface roughness of the cells (Figs. 1 and 2). These observations attest to the strength loss with low percentages of spacer.

\section{Porosity, stiffness and bending strength}

Figure 3 shows the porosity and relative density variation versus the addition ammonium carbonate. As expected, porosity is higher as the content of ammonium bicarbonate is increased. However, very similar porosity values for the same percentage of spacer were obtained, independently of the spacer particle size range and compaction pressure. Furthermore, due to the contraction $(\sim 30$ vol. $-\%)$ originated partially during the evaporation of the space holder and mainly during sintering, total porosity is lower than space holder volume fraction. Relative density (density of the porous material $\rho$ divided by that of the solid material $\rho_{\mathrm{s}}$ ) is higher than $0 \cdot 3$, so according to Asbhy ${ }^{18}$ these materials cannot be considered as foams but highly porous components.

As expected, stiffness was reduced as spacer content increased and there was not a clear tendency in relation to macropore size, as seen in Fig. 4. Stiffness of porous titanium containing porosities in the range of $20-60 \%$ was observed to vary from about 65 to $20 \%$ of the bulk sintered material, i.e. there is a clear inverse relationship. The lowest values of stiffness match those of human bone (cortical), ${ }^{5,7}$ which is of great importance to minimise stress shielding effect between implant and bone. According to Ashby, ${ }^{18}$ relative Young's modulus is related to the relative density of foams by the following equation

$1 \frac{E^{*}}{E_{\mathrm{s}}}=C\left(\frac{\rho^{*}}{\rho_{\mathrm{s}}}\right)^{\mathrm{n}}$

$C$ and $n$ are material dependent parameters. A coefficient $C$ close to $1(1 \cdot 037)$ together with an exponent of 1.62 is obtained from experimental values. As seen in Fig. 5, there is a close correlation between experimental and theoretical model. The fact that the coefficient $C$ is close to 1 is coherent with the fact that as the porosity is reduced, the stiffness of the material must tend to the 


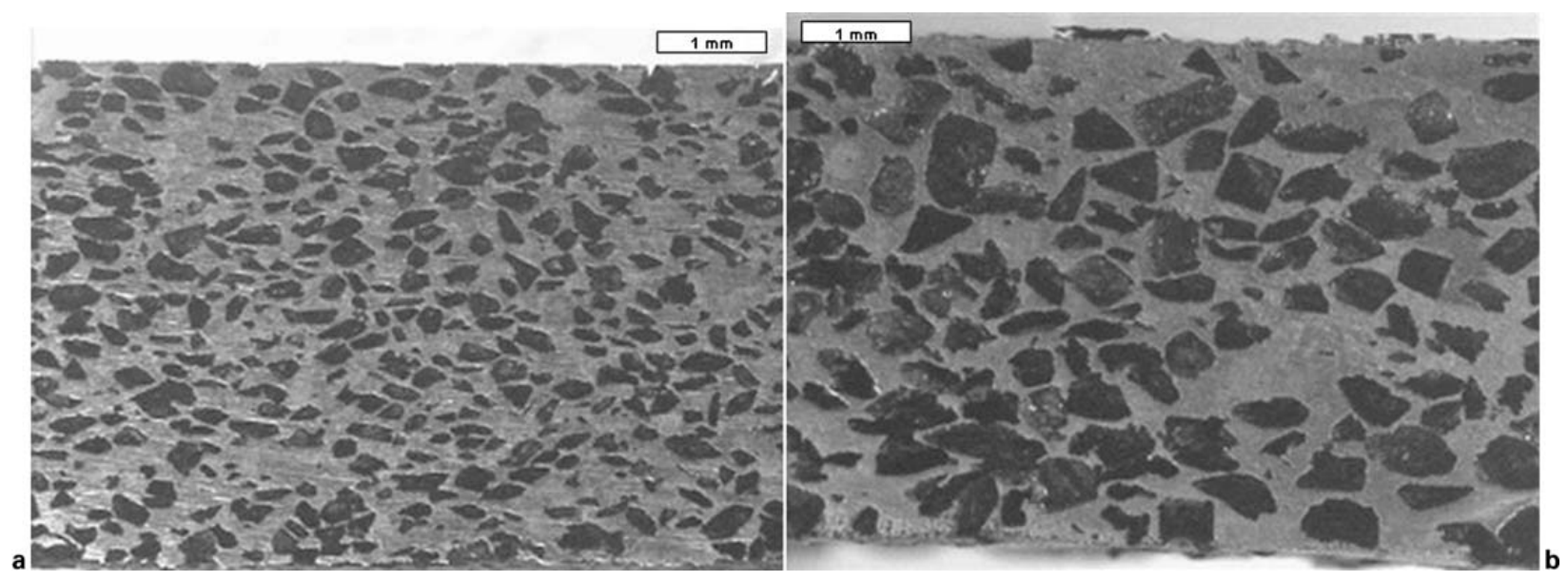

a spacer particle size range from 250 to $500 \mu \mathrm{m} ; b$ spacer particle size range from 500 to $1000 \mu \mathrm{m}$

2 Porous TiCP3 with 60 vol.-\% space holder particles, compacted at $200 \mathrm{MPa}$ and sintered: both figures have same magnification

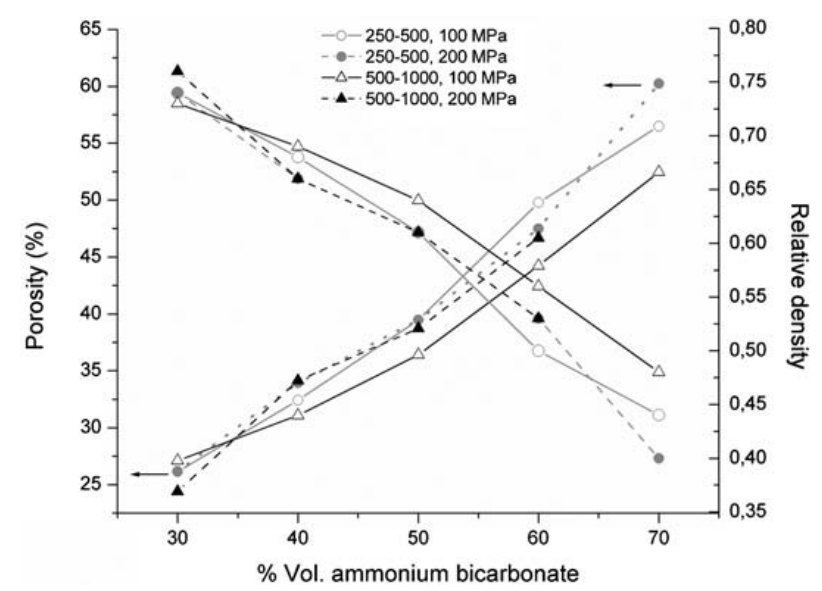

3 Total porosity and relative density of porous TiCP3 samples made with different amounts of ammonium bicarbonate and compaction pressures

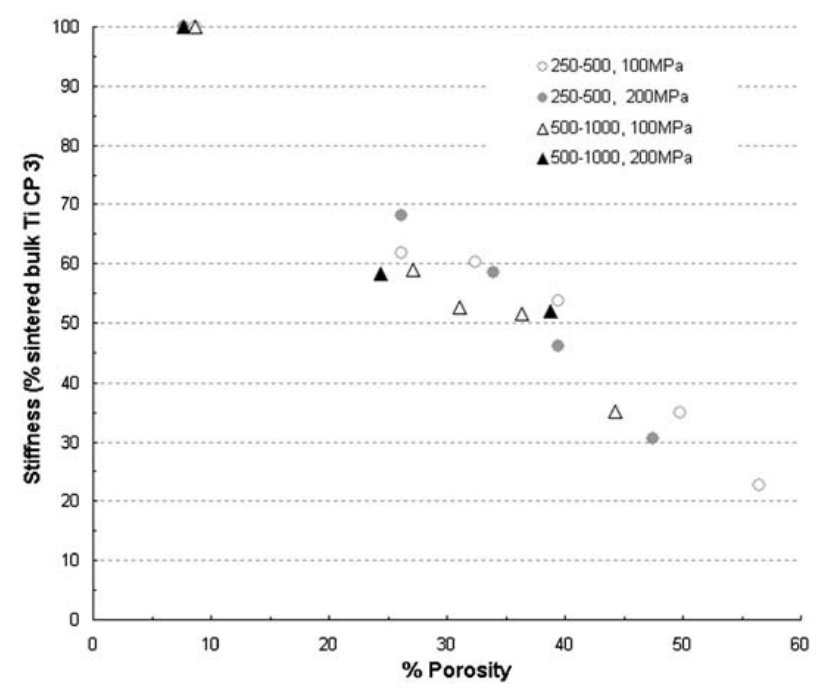

4 Relative stiffness as function of porosity

bulk value. This is in good agreement with the aforementioned fact that the authors are working in highly porous materials but not foams. The exponent value is close to that reported before by Bram $^{11}$ for similar materials but with different spacer size and characterised by compression testing. On the other hand, this value is much lower from that reported by Esen. ${ }^{10}$ However, in that work titanium powder consisted of spherical particles leading to a reduced neck size after sintering, which lead to a higher influence of the relative density on stiffness, i.e. for a given relative density ratio, a much lower relative stiffness is obtained.

Again, bending strength decreases as porosity increases, as expected (Fig. 6). There is also a significant strength loss between samples without spacer and with 30 vol. $\%$ of ammonium carbonate. As reported elsewhere, ${ }^{10,11}$ this effect might be mainly motivated by the microporosity as well as imperfections in porous material such as the irregular geometry and surface roughness of the cells or non-uniform pore density, which may degrade stiffness but to a higher extent strength. In this case, the spacer size plays a role in the flexural strength. For a specific compaction pressure and spacer quantity, bending strength is higher for the smaller spacer particle size. This effect can be attributed to two different effects. On the one hand, smaller spacers allow a better distribution of titanium powder between the macropores, as shown when comparing Fig. $2 a$ to $b$.

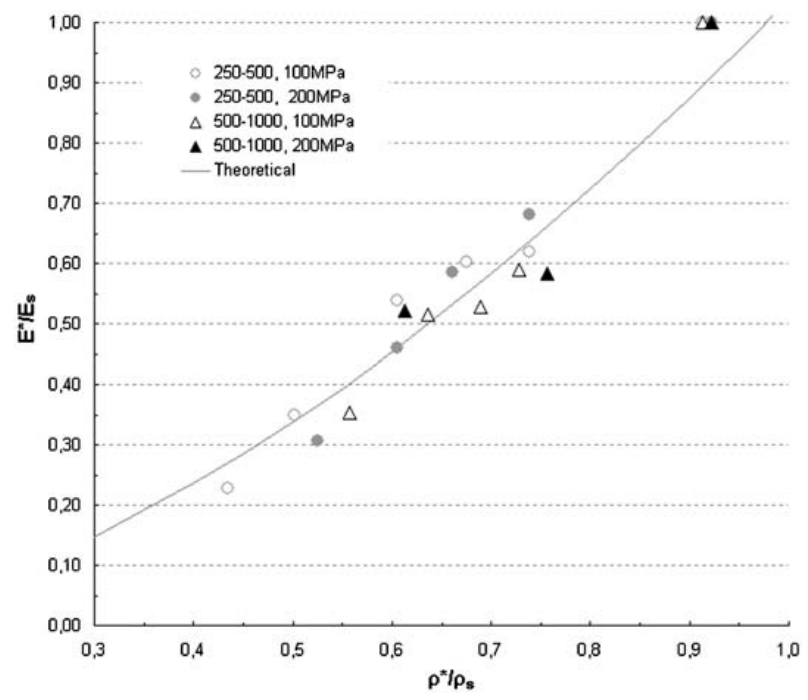

5 Relative stiffness to relative density: solid line represents values adjusted to $A$ shby ${ }^{18}$ model 


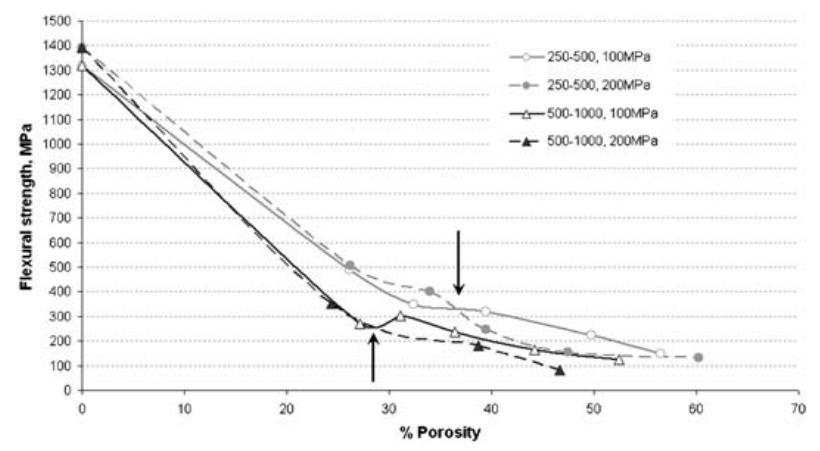

6 Flexural strength as function of porosity

On the other hand, larger spacer particles cause a higher degree of springback after compaction. In fact, for lower spacer fractions, yield strength increases with the compaction pressure, due to a higher packing of the green compact, facilitating sintering. However, when the spacer amount is higher than 35-40 vol.- $\%$, higher compaction pressures cause the deformation of the spacer particles reducing notch radius and increasing springback effects, that may lead to cracking. Again this effect is worse for bigger space holder particles $(500$ $1000 \mu \mathrm{m})$ than for smaller ones $(250-500 \mu \mathrm{m})$, where the aforementioned effect is observed for porosities higher than 29 and $37 \%$ respectively (Fig. 6).

\section{Conclusion}

In the present paper, porous TiCP3 specimens have been produced by the space holder method. The main process variables (compaction pressure, volume and spacer particle size) effects on bending strength and stiffness have been investigated.

Results show that ammonium carbonate spacer particles provide a means to retain large pores in the titanium sintered body. By burning out the spacer particles before sintering, titanium samples with up to $60 \%$ porosity levels have been realised by a traditional powder metallurgy route. Bending strengths higher than $100 \mathrm{MPa}$ and stiffness reduction up to $80 \%$ can be achieved, as required for bone substitute materials.
An important conclusion is the effect of spacer size on flexural strength. It has been shown that there is a negative effect of compacting pressure as the size of the space holder is increased, inversely as one would expect in common sintering practices. Furthermore, this effect appears at lower porosities for the larger spacers.

\section{References}

1. C. Leyens and M. Peters: 'Titanium and titanium alloys: fundamentals and applications'; 2003, Weinheim, Wiley-VCH.

2. M. Wehmöller, S. Weihe, C. Rasche, P. Scherer and H. Eufinger: Int. Congr. Ser., 2004, 1268, 667-672.

3. D. Rodriguez Rius: 'Obtención de capas de nitruro de titanio mediante tratamiento termoquímico en titanio y Ti6Al4V y caracterización de sus propiedades para aplicaciones biomédicas'; 1999, Barcelona, UPC.

4. A. Kostov and B. Friedrich: Comput. Mater. Sci., 2006, 38, 374 385.

5. B. D. Ratner, A. S. Hoffman, F. J. Schoen and J. E. Lemons: 'Biomaterials science: an introduction to materials in medicine'; 1996, San Diego, Academic Press.

6. G. Ryan, A. Pandit and D. P. Apatsidis: Biomaterials, 2006, 27, 2651-2670.

7. K. Asaoka and M. Kon: Mater. Sci. Forum, 2003, 426-432, 30793084.

8. K. E. Beljavin, V. K. Sheleg and D. V. Minko: Proc. PM2004 World Cong., Vienna, Austria, October 2004, EPMA, 7.

9. M. Köhl, M. Bram, H. P. Buckremer and D. Stöver: Proc. Conf. Euro PM2007, Toulouse, France, October 2007, EPMA, 129-134.

10. Z. Esen and S. Bor: Scr. Mater., 2007, 56, (5), 341-344.

11. M. Bram, S. H. Bogdanski, M. Koller, H. P. Buchkremer and D. Stover: Proc. Conf. Euro PM2005, Prague, Czech Republic, October 2005, EPMA, 517-522.

12. D. C. Dunand: Adv. Eng. Mater., 2004, 6, (6), 369-376.

13. N. Nomura, T. Kohama, I. H. Oh, S. Hanada, A. Chiba, M. Kanehira and K. Sasaki: Mater. Sci. Eng. C, 2005, C25, 330-335.

14. C. E. Wen, M. Mabuchi, Y. Yamada, K. Shimojima, Y. Chino and T. Asahina: Scr. Mater., 2001, 45, 1147-1153.

15. R. Cirincione, R. Anderson, J. Zhou, D. Mumm and W. O. Soboyejo: Proc. 3rd Global Symp. on 'Materials processing and manufacturing', (ed. A. K. Ghosh et al.), 189-198; 2002, Seattle, WA, TMS.

16. I. H. Oh, N. Nomura and S. Hanada: Mater. Trans., 2002, 43, 443446.

17. M. Thieme, K. P. Wieters, F. Bergner, D. Scharnweber, H. Worch, J. Ndop, T. J. Kim and W. Grill: J. Mater. Sci. Mater. Med., 2001, 12, 225-231.

18. M. Ashby, E. Michael, F. Tony, N. A. Gibson, L. J. Hutchinson and J. W. Wadley: 'Metal foams: a design guide', 6-54; 2000, Oxford, Butterworth-Heinemann. 


\section{Authors Queries}

Journal: Powder Metallurgy

Paper: 1453

Title: Analysis of bending strength of porous titanium processed by space holder method

Dear Author

During the preparation of your manuscript for publication, the questions listed below have arisen. Please attend to these matters and return this form with your proof. Many thanks for your assistance

\begin{tabular}{|l|l|l|}
\hline $\begin{array}{l}\text { Query } \\
\text { Reference }\end{array}$ & Query & Remarks \\
\hline 1 & $\begin{array}{l}\text { Author: Please cite Table 1 in } \\
\text { the text. }\end{array}$ & \\
\hline 2 & $\begin{array}{l}\text { Author: Please cite Refs. 13-17 } \\
\text { in the text. }\end{array}$ & \\
\hline
\end{tabular}

